\title{
Orthodontic Implant Failure: A Systematic Review
}

\author{
${ }^{1}$ Suchita S Daokar, ${ }^{2}$ Gauri Agarwal
}

\begin{abstract}
Objective: To use a systematic review to determine which all are the contributing factors that play role in success rate of orthodontic mini-implants.
\end{abstract}

Materials and methods: Different databases were searched without limitations up to July 2015. Additionally, the bibliographies of the finally selected articles were hand searched to identify any relevant publications that were not identified earlier. In vitro and in vivo articles were included. Both human and animal studies were included. Thirty five articles were initially selected, finally 28 articles were included in the study.

Conclusion: This review article conclude that success of orthodontic mini-implants depends on multiple factors which can be broadly classified under four headings- mechanical factors, biologic factors, placement technique, microbial factors. Mechanical factors included diameter of mini-implants, surface characteristics, load and its relation with implants, microgrooves, miniscrew versus manipulates, biologic factors included Inter-radicular space, skeletal growth pattern, placement site, racial factors, root proximity, placement techniques such as self-tapping and self-drilling placement, laser therapy, reinstalled mini-implants, pre drilling diameter play a vital role in success of implants. Microbial factors such as microbial floral changes after implant placement and inflammation surrounding the implants also have an important role in success and failure of implant.

Keywords: Anchorage, Mini-implants, Success rate.

How to cite this article: Daokar SS, Agarwal G. Orthodontic Implant Failure: A Systematic Review. Int J Oral Implantol Clin Res 2016;7(1):1-6.

Source of support: Nil

Conflict of interest: None

\section{INTRODUCTION}

Mini-implants are routinely used as absolute anchor devices while performing various orthodontic tasks, such as retraction of the anterior segment, mesiodistal movement of the posterior teeth, asymmetrical tooth movement, intrusive mechanics, and orthopedic corrections.

\footnotetext{
${ }^{1}$ Professor, ${ }^{2}$ Postgraduate Student

1,2Department of Orthodontics and Dentofacial Orthopaedics Chhatrapati Shahu Maharaj Shikshan Sanstha Dental College and Hospital, Aurangabad, Maharashtra, India
}

Corresponding Author: Suchita S Daokar, Professor Department of Orthodontics and Dentofacial Orthopaedics Chhatrapati Shahu Maharaj Shikshan Sanstha Dental College and Hospital, Aurangabad, Maharashtra, India, Phone: +91240643434, e-mail: suchitadaokar@gmail.com
However, after installation, some mini-implants show mobility before or during load application, which can lead to their removal or clinical failure. ${ }^{1}$ The failure rate of mini-implants varies from 6.6 to $16.1 \%$, which is higher than that of dental implants (3\%) and other temporary anchoring devices, such as miniplates $(2.6$ to $7.3 \%) .^{2-6}$ The mechanism that leads to mobility and, consequently, to the clinical failure of mini-implants is still unknown. ${ }^{6,7}$

The purpose of this article was to review and update current data on factors contributing to the success rate of mini-implants.

\section{MATERIALS AND METHODS}

A survey of articles published up to December 2015, associated with factors influencing success rates of mini-implants, was performed by using several electronic databases, such as Google Scholar, PubMed, EBSCO, Copernicus, Medline, and Embasse. The key words used to identify the corresponding studies in the database were peri-implantitis, mini-implant diameter, shape, self-drilling, self-tapping method, and role in success of mini-implants. Abstracts and summaries of these articles were reviewed to select papers. All the articles in English were selected. A total of 28 articles were selected in this process.

Inclusion criteria applied to the initial selection of the appropriate articles from the published abstracts consisted of:

- Various factors that affect success rates of orthodontic mini-implants - peri-implantitis, diameter of miniimplant, self-drilling, self-tapping method, placement site, placement side, interradicular space, vertical skeletal pattern, etc.;

- In vitro and in vivo studies;

- No case reports; and

- Studies published from 2000 to July 2015.

\section{RESULTS}

Initially, articles were selected according to the selection criteria from the various databases. From the 35 studies collected from all of the databases, only 28 studies actually fulfilled the inclusion criteria after the two reviewers examined each study. Among the 35 selected articles, 4 articles were rejected as they were review articles rather than experimental studies. Two articles were rejected as they were a case series or case report. One of the articles was rejected because it was a prospective study based on 
Flow Chart 1: Article selection

\begin{tabular}{|c|}
\hline $\begin{array}{c}\text { Electronic search (PubMed, Google Scholar, Medline, } \\
\text { EBSCO, Copernicus, Embase) } n=828\end{array}$ \\
\hline $\begin{array}{c}\text { (Articles excluded by title) } n=793 \\
\text { (Further abstracts were screened. Articles were } \\
\text { excluded if they were not on relevant topic, i.e, } \\
\text { review articles, case reports and } \\
\text { prospective studies) } n=7\end{array}$ \\
$\quad$ \\
Articles included in review 28 \\
\hline
\end{tabular}

perception. The final selection of studies include in vitro, in vivo, and animal studies. Flow Chart 1 presents the flow of article selection in this systematic review. About 28 articles satisfied the final selection criteria.

\section{FACTORS INFLUENCING SUCCESS RATES OF ORTHODONTIC MINI-IMPLANTS}

The success rate of orthodontic mini-implants depends on multiple factors. For the convenience and easy understanding of these factors, they are classified into four groups. They are:

1. Mechanical factors

2. Biologic factors

3. Placement technique

4. Microbial factors.

\section{Mechanical Factors}

\section{Diameter of Mini-implant}

Results from the study by Chen et $\mathrm{al}^{8}$ proved that when the self-drilling technique is used, micro-implants with a diameter of less than $1.3 \mathrm{~mm}$ are unsuitable for insertion into a bone with a density greater than 40 pounds per cubic foot. Barros et $\mathrm{al}^{9}$ proved that increase in mini-implant diameters significantly influenced the increase in the placement torque and fracture torque in quantities that progressively reduced the fracture risk. The self-drilling efficacy was not strongly influenced by diameter.

\section{Surface Characteristic}

Chaddad et $\mathrm{al}^{10}$ studied the survival rate of 17 machinedtitanium and 15 sandblasted-titanium mini-implants in 10 patients for a period of 150 days. They reported a survival rate of $87.7 \%$ and found that surface characteristics did not influence the survival rates of immediately loaded mini-implants.

\section{Microgrooves}

Kim et al ${ }^{11}$ conducted animal studies on Beagle dog by placing mini-implants of $1.6 \mathrm{~mm}$ diameter and $6.0 \mathrm{~mm}$ length. Both a nonmicrogroove (NMG) and a microgroove (MG) $(50 \mu \mathrm{m}$ pitch and $10 \mu \mathrm{m}$ depth) miniscrew were placed. They concluded that the success rate and bone-toimplant contact (BIC) on the pressure side were found to be higher in the MG group than in the NMG group. The MG group revealed no significant differences between BIC on the pressure and tension side, while the NMG did not show any difference. The MG exerts positive effects on soft-tissue adaptation and bone healing.

\section{Length of Mini-implants}

Sarul et $\mathrm{al}^{12}$ studied the effects of the length of miniimplants by placing both 6- and 8-mm-long mini-implants on the right and left sides of the mandible. They then concluded that $8 \mathrm{~mm}$ orthodontic miniscrew implants were significantly more stable than the $6 \mathrm{~mm}$ ones in the analyzed group.

\section{Effect of Applied Load on Mini-implants}

The clinical and biomechanical outcomes of titanium mini-implant systems activated with different load regimens were studied. Luzi et al ${ }^{1}$ conducted studies on animals (monkey) to determine the effect of immediate loading of orthodontic mini-implants on tissue, and concluded that loading seems to induce an earlier increase in bone formation and decrease in bone resorption. Therefore, loading with a light force is useful. Büchter et $\mathrm{al}^{13}$ also concluded that implants were lost only when load exceeded $900 \mathrm{cN} \mathrm{mm}$, and immediate loading of mini-implants can be done without loss of stability. For evaluation of the failure rate of immediately loaded mini-implants used for orthodontic anchorage, 140 miniimplants were placed at various sites in the maxilla and mandible for various movements like molar uprighting, molar uprighting and mesial movement, molar mesial movement, incisor intrusion and proclination, incisor retraction, premolar intrusion, midline correction, premolar distal movement, and molar intrusion and immediately loaded with $50 \mathrm{cN}$ superelastic coil springs. About 13 of the mini-implants failed $(9.3 \%)$ and 9 were partial failures, i.e., they showed minimum mobility, but stayed in place (6.4\%). The upper jaw had a greater failure rate $(12.2 \%)$ than the lower jaw $(8.0 \%)$. The palate was the anatomic location with the greatest risk of failure, while in the mandibular alveolar process, the least failure rate was observed. Hence, immediate loading with light forces should not be considered a risk factor.

\section{Characteristic of Retrieved Mini-implants}

Two of the studies focused on retrieved mini-implants. Eliades et a $1{ }^{14}$ studied retrieved mini-implants to observe 
any morphological, structural, or compositional alterations and hardness changes in the used mini-implants, and found that structural and morphologic changes occur. Tortamano et $\mathrm{al}^{15}$ studied periodontopathogens around the surfaces of retrieved mini-implants. When compared between the successful and failed mini-implant surfaces, it was found that there was reduction of Actinobacillus actinomycetemcomitans (Aa), Prevotella intermedia (Pi), and Porphyromonas gingivalis $(\mathrm{Pg})$ on the surface of the failed mini-implant. They, thus, concluded that the presence of $\mathrm{Aa}, \mathrm{Pi}$, and $\mathrm{Pg}$ around mini-implants is not associated with mobility.

\section{Miniscrew vs Miniplates}

A total of 140 mini-implants in 44 patients, including 48 miniplates and 92 freestanding miniscrews, were examined in the study. A variety of orthodontic loads were applied. The majority of the implants were placed in the posterior maxilla (104/140), and the next most common location was the posterior mandible (34/140). A cumulative survival rate of $89 \%(125 / 140)$ was found by Kaplan-Meier analysis. There was no significant difference in the survival rate between miniplates and freestanding miniscrews, but miniplates were used in more hazardous situations. The Cox proportional-hazards regression model identified anatomic location and periimplant soft-tissue character as two independent prognostic indicators. The estimated relative risk of implant failure in the posterior mandible was 1.101 (95\% confidence interval, 0.942 to $1.301 ; \mathrm{p}=0.046$ ). The risk ratio of failure for implants surrounded by nonkeratinized mucosa was 1.117 (95\% confidence interval, 0.899 to $1.405 ; \mathrm{p}=0.026$ ). The results confirmed the effectiveness of orthodontic mini-implants, but in certain situations adjustment of the treatment plan or modifications in the technique of implant placement may lead to improved success rates. ${ }^{16}$

\section{Biologic Factors}

\section{Placement Site}

Moon et $\mathrm{al}^{17}$ conducted a study on 209 orthodontic patients by placing mini-implants in interdental areas from the first premolar to the second molar in the maxilla and mandible and concluded that the success rate was independent of sex, age, jaw, soft-tissue management, placement side, and placement site in maxilla. However, the success rate in the mandible was dependent on the placement site of adult patients. Tsaousidis et $\mathrm{al}^{20}$ placed 20 mini-implants in the buccal and 18 in the palatal side of the maxilla, and 38 in the buccal side of the mandible at a minimum depth of at least $5 \mathrm{~mm}$. Miniscrews in the palatal side of the maxilla failed at a higher rate than in the buccal side of the mandible, so the insertion depth should be more than $5 \mathrm{~mm}$ on the palatal side. The failure rate was higher during the first 3 months after insertion while comparing the miniscrews in the buccal side of the maxilla or mandible. They observed the shorter miniscrews showed significantly higher failure rates and concluded that the insertion site seems to affect the failure rates of orthodontic miniscrews.

\section{Interradicular Space}

Asscherickx et $\mathrm{al}^{19}$ suggested that root contact and marginal position might be major risk factors for screw failure by placing 20 miniscrews into the mandible of 5 Beagle dogs between the roots of the second and third, and third and fourth premolars. After 25 weeks, the dogs were sacrificed to prepare histological slides. In five sites, the distance between the screw and the tooth was less than $1.0 \mathrm{~mm}$, but only one of these screws was lost. The distance between the screw and the marginal bone level was less than $1.0 \mathrm{~mm}$ for 9 screws and 7 of these were lost.

\section{Skeletal Growth Pattern}

The objective of the study conducted by Moon et $\mathrm{al}^{20}$ was to calculate the success rate of the mini-implants according to clinical variables (sex, age, soft-tissue management, placement position, sagittal skeletal classification, arch-length discrepancy, and side) and skeletal variables (articular angle, mandibular plane to palatal plane angle, Frankfort-mandibular plane angle, mandibular plane angle, gonial angle, upper gonial angle, and lower gonial angle). They concluded that vertical skeletal pattern might be an important factor for the success of orthodontic mini-implants placed in posterior buccal areas.

\section{Racial Factor}

Antoszewska et $\mathrm{al}^{2}$ studied the factors influencing the success rate of mini-implants by placing 350 self-tapped mini-implants in 130 patients and concluded that success rate in whites is greater than in Asians.

\section{Root Proximity}

Kuroda et al $^{21}$ examine 216 titanium screws in 110 patients using dental radiographs or cone beam computed tomography (CBCT). Each screw was classified according to its proximity to the adjacent root. In category I, the screw was absolutely separate from the root; in category II, the apex of the screw appeared to touch the lamina dura; 
and in category III, the body of the screw was overlaid on the lamina dura. Screws placed in the maxilla had a significantly higher success rate than those in the mandible. There was a significant correlation between success rate and root proximity. There were significant differences in the success rates between categories I and II, I and III, and II and III. Although screws in all three categories in the maxilla and categories I and II in the mandible showed high success rates above $75 \%$, screws in category III in the mandible had a low success rate of $35 \%$. They concluded that proximity of a miniscrew to the root is a major risk factor for the failure of screw anchorage. This tendency is more obvious in the mandible.

Chen et $\mathrm{al}^{22}$ performed an animal study on mongrels. Seventy-two miniscrews were surgically placed in the mandibular alveolar bone with metabolic bone labeling at 3-week intervals. In the experimental group, miniscrews were placed so that they contacted the root of the adjacent teeth. They studied the insertion torque, clinical measurements, removal torque, and histological findings and concluded that (1) there was high insertion torque with miniscrews contacting the roots; (2) the removal torque measurements varied on the basis of mobility of miniscrews and the type of root contact; and (3) there was more failure with miniscrews contacting the root.

\section{Placement Techniques}

\section{Self-tapping and Self-drilling Placement Techniques}

Çehreli and Arman-Özçırpıc1 ${ }^{23}$ placed mini-implants into the bovine iliac crest blocks after computed tomography (CT) assessment. It was concluded that differences in insertion torque values, Periotest values, and subjective assessments of stability scores of self-drilling and self-tapping implants were insignificant. Self-drilling implants had higher BIC percentages than did self-tapping implants. Significant correlations were found between parameters influencing the primary stability of the implants.

Yadav et $\mathrm{al}^{24}$ suggested that greater microdamage in the cortical bones of adult hounds in both the maxilla and the mandible was due to the self-drilling insertion technique as compared with the self-tapping technique. They placed mini-implants ( $\mathrm{n}=162$; diameter $1.6 \mathrm{~mm}$; length $6 \mathrm{~mm})$ in the maxillae and mandibles on both the right and left sides of nine hounds (12-14 months old) through the self-drilling and self-tapping insertion techniques.

The aim of Chen et al's ${ }^{3}$ retrospective study was to evaluate systematically the potential factors that influence failure rates of mini-implants used for orthodontic anchorage. They found that gender, type of malocclusion, facial divergency, implantation site (buccal, lingual, or crestal/ midpalatal), location (anterior or posterior), method of force application (power chain or NiTi coil spring), arch (upper or lower), type of soft tissue (attached gingiva or removable mucosa), and most of the cephalometric measurements that reflect dentocraniofacial characteristics do not affect the failure rates. An increased failure rate was noted for the self-drilling miniscrew type of temporary anchorage device (TAD), TADs used for tooth uprighting, those inserted on bone with lower density, those associated with local inflammation of the surrounding soft tissue, those loaded within 3 weeks after insertion, and those placed in patients with greater mandibular retrusion. Failure rates of the selfdrilling miniscrews installed by an oral surgeon and by an orthodontist did not differ significantly. They concluded that the inflammation of soft tissue surrounding a TAD and early loading within 3 weeks after insertion were the most significant factors predicting TAD failure. Both orthodontists and oral surgeons, who install orthodontic TADs, must undergo sufficient training to achieve clinical excellence.

\section{Laser Therapy}

Garcez et $\mathrm{al}^{25}$ did an animal study on pigs by placing miniscrews on the buccal side of the mandible and on the palate of the maxilla. They loaded them with $250 \mathrm{gm}$ force and irradiated the laser group with a 780-nm diode laser of $70 \mathrm{mWs}$ for $1 \mathrm{~min}$. The histological analysis and fluorescent microscopy after 3 weeks demonstrated that the laser group had less inflammatory cells than the control group, and the bone neoformation around the miniscrew was more intense and the success rate was $60 \%$ for the control group and $80 \%$ for the laser-treated group.

\section{Reinstalled Mini-implants}

Baek et $\mathrm{al}^{26}$ carried out a study by placing mini-implants in the attached gingiva of the upper buccal posterior regions for anchorage during en masse retraction. If it failed, a new one was immediately installed in the adjacent area or after 4 to 6 weeks in the same area. They concluded that the success rates of the newly placed mini-implants and that of the reinstalled ones were the same.

\section{Predrilling Diameter}

Wilmes et $\mathrm{al}^{27}$ conducted an animal study. In this study, after implant site preparation with different predrilling diameters $(1.0,1.1,1.2$, and $1.3 \mathrm{~mm})$, dual top screws 1.6-10 $\mathrm{mm}$ were inserted with three different insertion depths $(7.5,8.5$, and $9.5 \mathrm{~mm})$ in the 12 ilium bone segment of pigs. The insertion torque was recorded to assess primary stability. Higher insertion depths result in higher insertion torques and, thus, primary stability. Larger predrilling diameters result in lower insertion torques.

In the animal study of Tachibana et $\mathrm{al}^{28}$ the miniimplants were placed using self-drilling and predrilling 
methods into the ribs of pigs. Specimens were classified into two groups - cortical bone thicknesses of $1.2 \pm 0.02$ and $2.0 \pm 0.03 \mathrm{~mm}$ - respectively, and used to model the human maxillary and mandibular bones. The peak mini-implant placement torque value was measured, and the surrounding cortical bone was observed histologically. In the mandible model, the torque in the self-drilling and predrilling groups exceeded $10 \mathrm{~N} \mathrm{~cm}$, except in one case which had a 1.3-mm diameter pilot hole. Histology revealed cracks in the surrounding cortical bone in the groups whose torque value was $10 \mathrm{~N}$ cm or more. Therefore, when using the self-drilling technique to place a $1.6-\mathrm{mm}$ diameter miniimplant in the mandibular alveolar bone, it is preferable to drill a 1.3-mm diameter pilot hole first.

\section{Microbial Factors}

\section{Microbial Flora Changes after Placement of Mini-implant}

Two studies were found related to changes in microbial flora following insertion of orthodontic mini-implants. Uysal et $\mathrm{al}^{29}$ conducted a study to rule out the role of bacteremia in peri-implantitis. They reported no bacteremia in the pretreatment sample, but Streptococcus sanguis was positive in one of the postprocedure samples. Therefore, orthodontic mini-implant placement might be correlated to transient bacteremia, which may lead to failure of mini-implants. Determined that there was no significant difference in the microbial colonizations among the examined time intervals, except for Streptococcus spp., between baseline and 24 hours, which characterized the initial colonization in this time interval. Apel et $\mathrm{al}^{30} \mathrm{col}-$ lected bacterial samples of eight failed and four successful cases and subjected them to a universal bacteria-directed real-time quantitative polymerase chain reaction for quantification in combination with a microarray-based identification of 20 selected species. The bacterial analysis did not reveal any major difference in the total amount or species composition between control and failed miniimplants. However, Actinomyces viscosus was found in four $(100 \%)$ and Campylobacter gracilis in three (75\%) stable controls, whereas both species were rarely found (12.5\%) in failed implants. They concluded that the peri-implant sulcus surrounding failed orthodontic mini-implants did not show a specific aggressive bacterial flora.

\section{Bacteremia after Removal of Orthodontic Mini-implant}

Livas et $\mathrm{al}^{31}$ studied occurrence of bacteremia after removal of orthodontic mini-implants in human populations and found that there was no bacteremia in pre- and postblood samples.

\section{Inflammation}

Bae et $\mathrm{al}^{32}$ placed four types of 227 mini-implants in 87 consecutive patients and found that the screw-implant factors (type, diameter, and length), local host factors (occlusogingival positioning), management factors (angle of placement, onset and method of force application, ligature wire extension, exposure of screw head, and oral hygiene), and general host factors (age, sex) had no statistical significance.

However, mobility, jaw (maxilla or mandible), side of placement (right or left), and inflammation showed significant differences in success rates. Mobility, the right side of the jaw, and the mandible were the relative risk factors. To minimize the failure of screw implants, inflammation around the implant must be controlled, especially for screws placed in the right side of the mandible.

\section{CONCLUSION}

The success of orthodontic treatments depends upon the successful anchorage preparation. The introduction of orthodontic implants has opened new horizons in intraoral anchorage systems. Orthodontic implants are placed temporarily (for anchorage purpose) in the oral cavity in comparison with dental implants; however, orthodontic implants face a higher risk of failure. An insight into the etiological factors contributing to this failure is an important aspect for successful orthodontic treatment. A systematic review undertaken here has enlightened the risk factors to be taken into consideration to achieve success in orthodontic implants.

\section{REFERENCES}

1. Luzi C, Verna C, Melsen B. Immediate loading of orthodontic mini-implants: a histomorphometric evaluation of tissue reaction. Eur J Orthod 2009 Feb;31(1):21-29.

2. Antoszewska J, Papadopoulos MA, Park HS, Ludwig B. Five-year experience with orthodontic miniscrew implants: a retrospective investigation of factors influencing success rates. Am J Orthod Dentofacial Orthop 2009 Aug;136(2):158.e1-158. e10.

3. Chen YJ, Chang HH, Lin HY, Lai EH, Hung HC, Yao CC. Stability of miniplates and miniscrews used for orthodontic anchorage: experience with 492 temporary anchorage devices. Clin Oral Implants Res 2008 Nov;19(11):1188-1196.

4. Miyawaki S, Koyama I, Inoue M, Mishima K, Sugahara T, Takano-Yamamoto T. Factors associated with the stability of titanium screws placed in the posterior region for orthodontic anchorage. Am J Orthod Dentofacial Orthop 2003 Oct;124(4):373-378.

5. Morea C, Dominguez GC, Tortamano A, Vigorito JW. Frequency and cause of failure of miniscrews for orthodontic absolute anchorage. Eur J Orthod 2007;29:e27-e28.

6. Schatzle M, Roland M, Zwahlen M, Lang N. Survival and failure rates of orthodontic temporary anchorage devices: a systematic review. Clin Oral Implants Res 2009 Dec;20(12):1351-1359. 
7. Feldmann I, Bondemark L. Orthodontic anchorage: a systematic review. Angle Orthod 2006 May;76(3):493-501.

8. Chen Y, Kyung HM, Gao L, Yu WJ, Bae EJ, Kim SM. Mechanical properties of self drilling orthodontic micro-implants with different diameters. Angle Orthod 2010 Sep;80(5): 821-827.

9. Barros SE, Janson G, Chiqueto K, Garib DG, Janson M. Effect of mini-implant diameter on fracture risk and self-drilling efficacy. Am J Orthod Dentofacial Orthop 2011 Oct;140(4): e181-e192.

10. Chaddad K, Ferreira AF, Geurs N, Reddy MS. Influence of surface characteristics on survival rates of mini-implants. Angle Orthod 2008 Jan;78(1):107-113.

11. Kim TW, Baek SH, Kim JW, Chan YI. Effects of microgrooves on the success rate and soft tissue adaptation of orthodontic miniscrews. Angle Orthod 2008 Nov;78(6):1057-1064.

12. Sarul M, Minch L, Hyo-Sang Park HS, Antoszewska-Smith J. Effect of length of orthodontic mini-screw implants on their long term stability: a prospective study. Angle Orthod 2015 Jan;85(1):33-38.

13. Büchter A, Wiechmann D, Gaertner C, Hendrik M, Vogeler M, Wiesmann HP, Piffko J, Meyer U. Load-related bone modeling at the interface of orthodontic micro-implants. Clin Oral Implants Res 2006 Dec;17(6):714-722.

14. Eliades T, Zinelis S, Papadopoulos MA, Eliades G. Characterization of retrieved orthodontic miniscrew implants. Am J Orthod Dentofacial Orthop 2009 Jan;135(1):10.e1-10.e7.

15. Tortamano A, Dominguez GC, Haddad AC, Nunes FD, Nacao M, Morea C. Periodontopathogens around the surface of mini-implants removed from orthodontic patients. Angle Orthod 2012 Jul;82(4):591-595.

16. Cheng SJ, Tseng IY, Lee JJ, Kok SH. A prospective study of the risk factors associated with failure of mini-implants used for orthodontic anchorage. Int J Oral Maxillofac Implants 2004 Jan-Feb;19(1):100-106.

17. Moon CH, Lee DG, Lee HS, Im JS, Baek SH. Factors associated with the success rates of orthodontic miniscrew placed in upper and lower posterior region. Angle Orthod 2008 Jan;78(1):101-106.

18. Tsaousidis G, Bauss O. Influence of insertion site on the failure rates of orthodontic miniscrews. J Orofac Orthop 2008 Sep;69(5):349-356.

19. Asscherickx K, Vannet BV, Wehrbein H, Sabzevar MM. Success rate of miniscrew relative to their position to adjacent roots. Eur J Orthod 2008 Jul;30(4):330-335.

20. Moon CH, Park HK, Nam JS, Im JS, Baek SH. Relationship between vertical skeletal pattern and success rate of orthodontic mini-implants. Am J Orthod Dentofacial Orthop 2010 Jul;138(1):51-57.

21. Kuroda S, Yamada K, Deguchi T, Hashimoto T, Kyung HM, Takano Yamamoto T. Root proximity is the major factor for screw failure in orthodontic anchorage. Am J Orthod Dentofacial Orthop 2007 Apr;131(Suppl 4):S68-S73.

22. Chen YH, Chang HH, Chen YJ, Lee D, Chiang HH, Yao CC. Root contact during insertion of miniscrews for orthodontic anchorage increases the failure rate: an animal study. Clin Oral Implants Res 2008 Jan;19(1):99-106.

23. Çehreli S, Arman-Özçırpıcı A. Primary stability and histomorphometric bone-implant contact of self-drilling and self-tapping orthodontic microimplants. Am J Orthod Dentofacial Orthop 2012 Feb;141(2):187-195.

24. Yadav S, Upadhyay M, Liu S, Roberts E, Neace WP, Nanda R. Microdamage of the cortical bone during mini-implant insertion with self-drilling and self-tapping techniques: a randomized controlled trial. Am J Orthod Dentofacial Orthop 2012 May;141(5):538-546.

25. Garcez AS, Suzuki SS, Martinez EF, Iemini MG, Suzuki H. Effects of low-intensity laser therapy over mini-implants success rate in pigs. Laser Med Sci 2015 Feb;30(2):727-732.

26. Baek SH, Kim BM, Kyung SH, Lim JK, Kim YH. Success rate and risk factors associated with mini-implants reinstalled in the maxilla. Angle Orthod 2008 Sep;78(5):895-901.

27. Wilmes B, Drescher D. Impact of insertion depth and predrilling diameter on primary stability of orthodontic mini-implants. Angle Orthod 2009 Jul;79(4):609-614.

28. Tachibana R, Motoyoshi M, Shinohara A, Shigeeda T, Shimizu N. Safe placement technique for self drilling orthodontic mini-implants. Int J Oral Maxillofac Surg 2012 Nov;41(11): 1439-1444.

29. Uysal T, Yagci A, Esel D, Ramoglu SI, Kilinc A. Investigation of bacteremia following insertion of orthodontic mini-implants. World J Orthod 2010 Winter;11(4):357-361.

30. Apel S, Apel C, Morea C, Tortamano A, Dominguez GC, Conrads G. Microflora associated with successful and failed orthodontic mini-implants. Clin Oral Implants Res 2009 Nov;20(11):1186-1190.

31. Livas C, Delli K, Karapsias S, Pandis N, Ren Y. Investigation of bacteremia induced by removal of orthodontic mini-implants. Eur J Orthod 2014 Feb;36(1):16-21.

32. Bae SM, Park HS, Kyung HM, Kwon OW, Sung JH. Clinical application of micro-implant. Anchorage. J Clin Orthod 2002 May;36(5):298-302. 